Open Access

\title{
Categorizing households into different food security states in Nigeria: the socio- economic and demographic determinants
}

Kolawole Ogundari

Correspondence:

ogundarikolawole@daad-alumni.de Department of Applied Economics and Statistics, University of

Delaware, Newark, USA

\begin{abstract}
The literature reiterates the need to employ indicators that reflect the multidimensional nature of food security. In a quest to capture the multidimensional nature of food security, this study uses a novel ideal that harmonizes two food security indicators (food expenditure (FOOD $\mathrm{exp}_{\mathrm{p}}$ ) and dietary diversity score (DDS)) to categorize households into different levels of food security states in Nigeria. In addition, the study also examined factors that influence the probability of households being in different levels of food security states in the country. Our estimates show that about 66 and $60 \%$ of the households in the sample were food secure based on a single indicator such as FOOD exp and DDS, respectively. However, by harmonizing the two indicators, results reveal that about $42 \%$ of the households are actually food secure. The implication of this is that about 24 and $18 \%$ of the households are transitory food insecure. Results also suggest that the use of a single indicator may wrongly classify households as food secure instead of categorizing them as transitory food insecure. Furthermore, the empirical results show that households that consume only home produced food have high probabilities of being food insecure, while households that consume only market-purchased food are less likely to be food insecure. The implication of this finding is that harmonization of food security indicators helps identify households with different nature of food (in) security problems that require different types of policy interventions most especially in Nigeria. The results of the empirical analysis also imply that market-based intervention policies that facilitate households' access at all time to healthy foods of their choice should be given priority. This gives the household opportunity to benefit from greater varieties of food items offered by the market.
\end{abstract}

Keywords: Dietary diversity, Food security, Food expenditure, Determinants, Household, Nigeria

JEL classification: D12, D13, Q12

\section{Background}

Food is key to sustaining life, as it provides nutrients essential for the maintenance of good health, improvement of wellbeing, and labour productivity. Food insecurity is a global issue that seems to be most severe in Africa and especially sub-Saharan region of Africa. For instance, during the periods 2014 and 2016, the level of undernourishment in

(c) The Author(s). 2017 Open Access This article is distributed under the terms of the Creative Commons Attribution 4.0 International License (http://creativecommons.org/licenses/by/4.0/), which permits unrestricted use, distribution, and reproduction in any medium, provided you give appropriate credit to the original author(s) and the source, provide a link to the Creative Commons license, and indicate if changes were made. 
sub-Saharan Africa rose to about 220 million when compared to 180 million recorded between 1990 and 1992 (Food and Agricultural organization 2015).

"Food security exists when all people, at all times, have physical and economic access to sufficient, safe, and nutritious food to meet their dietary needs and food preferences for an active healthy life" (Food and Agricultural organization 1996). This definition reinforces the multidimensional nature of food security which includes availability, access, utilization, and sustainability. Availability connotes physical presence of food in adequate amount; accessibility implies efficient purchasing power at all times; utilization reflects the demand for sufficient quantity and quality of food intake; and sustainability refers to the adequacy of food at all times. A number of food security indicators at the micro-level have been identified in the literature (Lokosang et al. 2011; Pangaribowo et al. 2013; Obayelu 2013; Yu and You 2013). Some of these indicators include per capita food consumption (such as per capita nutrient intakes of calorie, protein, and fat), per capita expenditure on food, dietary diversity score/food consumption score, coping strategy index, share of dietary intake, food insecurity access scale (self-report/assessment), and anthropometry measures among others.

However, an issue that has emanated from the literature is whether there exists an indicator of food security that satisfies the multidimensional nature of food security as specified by the definition (Magrini and Vigani 2014). Unfortunately, no single indicator can incorporate all the dimensions of food security (Hoddinot 1999), because a combination of measures and indicators are needed to fully reflect the complex reality of food insecurity problem in any given context (Carletto et al. 2013). Similarly, Habicht and Pelletier (1990) argued that there is no best indicator because the characterization of an indicator in a generic sense as "best" depends ultimately on whether or not it is the most appropriate for the decision to be made.

Despite the variety of food security indicators that exist in the literature, there is lack of consensus on the core household food security indicators that are needed to adequately measure and monitor food security situation around the world both at the micro- and macro-level (Carletto et al. 2013), given that these indicators only focus on one dimension at a time. The absence of an all-encompassing indicator of food security limits the extent to which panoptic food security policies can be made from existing studies. For example, the use of crop yield indicates availability; food consumption and food expenditure denote food accessibility; dietary diversity, anthropometric measures, and food consumption score reflect food utilization; and coping strategy index represents food sustainability among others. The implication of this is that the choice among available food security indicators involves a trade-off, as concept of food security is inherently hierarchical (Barret 2010). Thus, food availability is necessary but not sufficient for food accessibility; food accessibility is necessary but not sufficient for food utilization; and food utilization is necessary but not sufficient for food sustainability.

The absence of more generalized indicators that incorporate more than one dimension of the concept of food security led to the conceptualization of this study. This study harmonizes indicators of food security in order to reflect its multidimensional and also derive clearer policy conclusions from the analysis. This approach could help to categorize households into different levels of food security states. The categorization of households into different levels of food security has a number of policy implications: First, it ensures proper identification of households into different states or levels of 
food security. Second, it provides opportunities to target households with appropriate food policy intervention. Third, it helps channel policy instruments specifically to households that are most vulnerable.

This study proposes a relatively more encompassing indicator of food security, which incorporates the food accessibility and utilization aspect of food security definition. Due to lack of information on variables representing food availability and sustainability dimensions of food security in the dataset, other aspects of food security are not included in the present study. Hence, we combine (harmonize) two indicators of food security, namely: food expenditure $\left(\mathrm{FOOD}_{\mathrm{exp}}\right)$ and the dietary diversity score (DDS) which represent food accessibility and food utilization, respectively. The choice of these indicators for the present study is motivated by two factors. First, these indicators have been widely used in many empirical literatures on food security in the developing countries. Second, these indicators incorporate different dimensions of the concept of food security. Moreover, we believe that limitation in data used for the study may be responsible for the first point, as our data only contains information on expenditure on the variety of food items in the household food basket. Detailed information on nutrient intakes, coping strategy, anthropometric measures, or quantity of food consume by the households among others to construct other dimensions of food security indicators are generally not available in most of the World Bank supported Living Standard Survey (NLSS) data from the developing countries, which we use in the present study.

Harmonization of the two indicators provides the opportunity to stratify (categorize) households in the sample into different states of food security based on acceptable thresholds for food expenditure and dietary diversity score. Households that jointly pass both thresholds are classified into the food secure class; households that fall below both thresholds are categorized as food insecure; while households that pass only one of the thresholds are grouped into different transitory classes of food security. The study further examined the demographic and socio-economic determinants of household dietary diversity (DD) represented by dietary diversity score (DDS) and dietary diversity index (DDI). Also of particular interest in this study is the importance of home-produced and market-purchased food in the reduction of food insecurity. Particularly, we examined the impact of purchased and home-produced food on the probability of being food insecure.

The rest of the paper is organized as follows. The next section describes food security indicators used in the study. "Theoretical framework" focuses on the theoretical framework of the study. "Empirical model" describes the data used in the study. "The data description" presents the empirical model, while "Results and discussion" presents and discusses the results. Concluding remarks are made in the "Conclusions".

\section{Food security indicators in the study}

Per capita food expenditure

The use of per capita food expenditure $\left(\mathrm{FOOD}_{\exp }\right)$ as an indicator of food security has been widespread. It is often used in measuring food accessibility (Smith and Subandoro 2007; Faridi and Wadood 2010). While Hendriks and Msaki (2009) argue that expenditure on food reflects both the concepts of food accessibility and to some extent, the 
degree of vulnerability to food insecurity, Faridi and Wadood (2010) suggest that higher expenditure proportions are only essential indicators of inter-temporal vulnerability to food insecurity. As a result, food expenditure proxies' food accessibility dimension of food security because food prices and household resources affect the extent to which households have economic access to food. Expenditure on food does not provide any information on the nutritional quantity that household consume, but rather, it reflects the extent to which households' resources affect the amount of food consumed. Similar to the work of Canagarajah and Thomas (2001) and Omonona and Adetokunbo (2007), this study uses the weighted two thirds of the mean of per capita expenditure as a threshold so that a household is referred to as food secure (or food insecure) when the observed per capita food expenditure is greater (or less) than the threshold.

\section{Dietary diversity score and dietary diversity index}

Dietary diversity score (DDS) measures the degree to which the variety of food consumed by households differs in terms of nutrient intakes over a given period of time. The DDS suggest that households gain satisfaction on food consumed not only because "more is better", but because "variety, which DDS represents, is the spice of life". According to USDA-ERS (2012), higher DDS means a household is consuming a diet that is diverse and whose quality is sufficient to supply important micronutrients. The movement of a household from a restricted to diverse diet is often a function of increased income. For instance, it is easy to observe that household meat consumption increases with higher income (Roberts and Schlenker 2010). Thus, DDS represents the food utilization dimension of the food security (Magrini and Vigani 2014). Heady and Ecker (2012) also referred to DDS as an effective indicator of food utilization for two reasons. First, it reflects consumption of both macro- and micronutrients. Second, demand theory suggests that individuals or households that allocate their resources towards higher-quality foods when they have satisfied their basic caloric needs, attain a higher level of utility. However, a major limitation of DDS is its failure to account for the quantity of nutrient consumed by the households. Nevertheless, empirical studies suggest there is a close correlation between DDS and anthropometric measures, which are examples of indicators that take into account the quantities of nutrients consumed in the household diet (Hoddinot and Yohannes 2002). Hence, unlike expenditure on food, DDS accounts for dietary quality both at the individual and household levels (Ruel 2012). Thus, similar to the work of Smith and Subandoro (2007), we consider a household as food insecure (food secure) if their DDS is less (greater) than the average DDS of the households in the upper quartile.

Although traditional demand theory suggests the use of dietary diversity index (DDI) instead of DDS in accounting for consumers' preferences for various food items, DDS has been widely used in many empirical studies. Drescher et al. (2007) also argue that unlike DDI, DDS do not account for the distribution of food groups to reflect the extent of dietary diversification in the household dietary demand. While we acknowledge these limitations of DDS, it is very easy to construct and this may explain why it is widely adopted in food security studies. DDI is an index that ranges between 0 and 1. While DDS is computed from the share of household expenditure on the identified food groups in the household food basket, DDI reflects food utilization dimension of food security. 


\section{Household level food security states}

This study harmonizes two indicators representing food accessibility and food utilization dimensions of food security. Weighted two thirds of the mean of food expenditure and average DDS of the households in the upper quartile are used as predetermined thresholds to stratify households into different levels of food security. Thus, this study harmonizes the two indicators in order to classify households into four mutually exclusive levels of food security states. The levels include (1) households that are completely food insecure, (2) transitory food insecure based on FOOD exp $_{\text {, although }}$ food secure based on DDS, (3) transitory food insecure based on DDS, although food secure based on FOOD exp , and (4) completely food secure state as evident from both indicators.

\section{Theoretical framework}

The theoretical framework for modeling the determinants of household food security is, in general, built within the framework of household utility model. Following the work of Singh et al. (1986), we recognize that some households are both consumers and producers of their food and thus, model household utility within the framework of consumer demand and production theories as follows:

$$
U_{i}=u\left(C_{i}, l_{i} \mid x_{i}\right)
$$

where $U_{i}$ is a utility function that is twice differentiable, increasing in its arguments, and strictly quasi-concave; $C_{i}$ is a vector of the $i$ th household's consumption demand, which include food $C_{f}$, and non-food $C_{n f}, l_{i}$ is the time devoted to leisure and $x_{i}$ is the vector of household socio-demographic variables that we include, in order to recognize that household utility is derive from the combination of decisions made by household members according to their preferences.

Given the foregoing definition of $C_{i}$, it can be specified as:

$$
C_{i}=\left(C_{f}, C_{n f}\right)
$$

As some households are both consumers and producers of food, $C_{f}$ can be further considered as a vector of home-produced food $f_{\mathrm{hp}}$ and $f_{\mathrm{mp}}$ and market-purchased food $f_{\text {mp }}$. Again, within this context, $C_{f}$ can be stated as follows:

$$
C_{f}=\left(f_{h p}, f_{m p}\right)
$$

Substituting Eqs. 2 and 3 into Eq. 1 gives Becker's (1981) generalized utility function defined as:

$$
\begin{aligned}
& U_{i}=u\left[\left(C_{f}, C_{n f}\right)^{\prime}, \quad l_{i} \mid x_{i}\right] \\
& U_{i}=u\left[\left[\left(f_{h p}, f_{m p}\right)^{\prime}, \quad C_{n f}\right]^{\prime}, \quad l_{i} \mid x_{i}\right]
\end{aligned}
$$

For those households that produce food which they also consume and that are consequently subject to certain constraints of production, income and time factors, the optimization of Eq. 4b requires that household's production and consumption decisions are made separately on the assumption that they are all relevant to the market. In this 
case, production decisions are first made and then subsequently used in allocating the income between consumption of goods and leisure (Strauss 1983). According to Feleke et al. (2005), it is important to make this assumption because food security or food consumption often depends on production variables, but not vice versa.

Similar to the work of Singh et al. (1986), the production, income, and time constraints imposed in the course of optimizing Eq. $4 \mathrm{~b}$ can be specified as follows:

\section{Production constraint}

$$
f\left(Q_{h p}, L, A^{0}, K^{0}\right)=0
$$

Equation 5 is a typical household production function for food $Q_{\mathrm{hp}}$ produced at home and assumed to be twice differentiable, increasing in outputs, decreasing in inputs, and strictly convex; $A^{0}$ is the farm size; $K^{0}$ is the fixed capital stock; $L$ is total labour used on the farm.

\section{Income constraint}

$$
P_{h p}\left(Q_{h p}-f_{h p}\right)-P_{m p} f_{m p}-P_{n f} C_{n f}-w\left(L-l_{f}\right)+N=0 f\left(Q_{h p}, L, A^{0}, K^{0}\right)=0
$$

From Eq. 6, $P_{h p}$ is the price of food produced, $Q_{h p}-f_{h p}$ is the marketed surplus of food produced; $w$ is the wage rate; $l_{f}$ is the total family labour supply on the farm; $P_{m p}$ is the price per unit of market-purchased food items; $P_{n f}$ is the price per unit of nonfood item; $P_{h p}$ is the price per unit of marketed surplus of food produced; $C_{n f}$ is the demand for non-food items such as education, health, housing, etc.; $w$ is the wage for hired labour; $N$ is the non-farm income adjusted to ensure that Eq. 6 equal to zero.

\section{Time constraint}

$$
\begin{aligned}
& T=l_{f}+l \\
& l_{f}=T-l
\end{aligned}
$$

where $T$ is household's time endowment received in each time period, which is allocated between leisure $l$ and time spent working on the farm $l_{f}$.

Substituting the right-hand side (RHS) of Eq. $7 \mathrm{~b}$ into 6 gives:

$$
P_{h p}\left(Q_{h p}-f_{h p}\right)-P_{m p} f_{m p}-P_{n f} C_{n f}-w(L-T+1)+N=0
$$

Expanding Eq. 8 gives:

$$
P_{h p} Q_{h p}-P_{h p} f_{h p}-P_{m p} f_{m p}-P_{n f} C_{n f}-w L+w T-w l+N=0
$$

Re-arranging Eq. 9 to explicitly account for household income and expenditure gives:

$$
\underbrace{P_{h p} Q_{h p}+w T+N-w L}_{\text {HH Income }}=\underbrace{P_{h p} f_{h p}+P_{m p} f_{m p}+P_{n f} C_{n f}+w l}_{\text {HH Expenditure }}
$$

Equation 10 shows that the left-hand side (LHS) equals household income ( $\mathrm{HH}$ income). The household income comprises of the value of farm produce $P_{h p} Q_{h p}$, value of HH's time endowment $w T$, the value of labour used $w L$, and non-farm income $N$. 
Likewise, the RHS is equivalent to household expenditure (HH expenditure). The household expenditure includes the value of home produce food consumed $P_{h p} f_{h p}$; value of market purchase food consumed $P_{m p} f_{m p}$; value of non-food expenditure $P_{n f} C_{n f}$ and purchase of leisure $w l$. The optimization of Eq. $4 \mathrm{~b}$ gives rise to income and expenditure equation within the separability assumption, which is necessary to have first order conditions. It is equally possible via optimization of Eq. 10 to yield production and consumption equations separately. This is discussed below.

The demand for inputs and output produced, especially for households that produced their food at home, can be derived by maximizing the first-order condition of the LHS of Eq. 10 with respect to labour $(L)$ and output produced $(Q)$ as:

$$
\begin{aligned}
& L^{*}=l^{*}\left(P_{h p}, w, A^{0}, K^{0}\right) \\
& Q^{*}=Q_{h p}^{*}\left(P_{h p}, w, A^{0}, K^{0}\right)
\end{aligned}
$$

where $L^{*}$ is the optimum labour used and $Q^{*}$ is the optimum output. Substituting Eqs. 11 and 12 into LHS of Eq. 10 gives optimum income/full income $Y^{*}$ under the assumption of maximized profit $\pi^{*}$ as:

$$
\begin{aligned}
& Y^{*}=P_{h p} Q^{*}+w T+N-w L^{*} \\
& Y^{*}=w T+\pi^{*}\left(P_{h p}, w, A^{0}, K^{0}\right)+N
\end{aligned}
$$

where, $\pi^{*}\left(P_{h p}, w, A^{0}, K^{0}\right)=P_{h p} Q^{*}-w L$

Household's demand for food $C_{f}$ can be derived by solving the first-order conditions of the RHS of Eq. 10. However, recall in Eq. 3 that $C_{f}$ is a vector of $f_{h p}$ and $f_{m p}$ which, in turn, depend on their respective prices. This relationship can be specified as:

$$
C_{f}=c_{f}\left(P_{h p}, P_{m p}, P_{n f}, w, Y^{*}\right)
$$

Household demand for food also depends on the preferences of its members. These preferences are represented by household demographic characteristics in Eq. 14. Thus, in line with Eq. 13b, we can further specify $Y^{\prime \prime}$ in Eq. 14 as:

$$
C_{f}=c_{f}\left(P_{h p}, P_{m p}, P_{n f}, w, Y^{*}\left(P_{h p}, w, A^{0}, K^{0}, N\right) \mid x\right)
$$

where,

$$
f=h p, m p
$$

Equation 15 suggests that household food consumption $\mathrm{C}_{f}$ depends on both food and non-food prices, wages, and household income. Thus, if household demand for food could be referred to as a measure of household food security (FS), then $\mathrm{C}_{f}$ is a reduced form of the utility function in Eq. 1. It allows the evaluation of the effects of household level characteristics as well as economic factors such as income. The relationship can be represented by:

$$
C_{f} \approx F S_{i}=\left[\mathrm{FOOD}_{\exp }, N T, D D S / D D I, \ldots \text { etc }\right]^{\prime}
$$

where $F S$ is taken as a vector of various indicators of household food security, which could be food expenditure FOOD ${ }_{\text {exp }}$, nutrient intake $N T$ such as calorie, protein and other food nutrients, dietary diversity score $D D S$ or dietary diversity index $D D I$, and production 
index (Smith and Subandoro 2007; Lokosang et al. 2011; Obayelu 2013; Pangaribowo et al. 2013).

\section{Methods}

\section{Empirical model}

The empirical model is defined within the framework of Eq. 15. Unfortunately, lack of information on prices as a possible determinant of FS somewhat limits the scope of the study. Hence, we re-parameterize the relationship between household food security $F S$ and its determinants using a reduced form equation in which food and non-food prices are excluded. In this regard, the reduced equation is designed to consider only the socio-economic (income) and demographic (age, education, and proportion of household member by age, etc.) determinants of household food security. This approach of examining the role of demographic determinants other than food prices in explaining food security have been widely adopted in food security literature due to lack of data on food prices in the survey used for the respective studies (see Magana-Lemus et al. 2016; Rose and Chariton 2002; Obayelu 2013).

The empirical specification of the reduced form of Eq. 15 without the food and nonfood prices is stated as follows:

$$
F S_{i}=\left(Y_{i}^{*}, x_{i} \mid \phi, \beta\right)+\eta_{i}
$$

where FS is a vector representing categorical variables denoting household level of food security states (FS_states) derived from the combination of two food security indicators, DDS and DDI. $Y^{*}$ represents household income; $x$ is a vector of household demographic variables, $\phi$ and $\beta$ are the parameters to be estimated, and $\eta$ is the error term of the regression. The subsequent subsection focuses on the econometric approach employed to examine the determinants of each component of FS, outlined above as well as how DDS and DDI were constructed in the study.

\section{Determinants of households in different levels of food security states [FS_states]}

We assess the determinants of the levels of household food security states using a multinomial logit model. The dependent variable, in this case is the discrete or categorical variable represented by FS_states. According to Rose and Chariton (2002), this type of regression is a generalization of the familiar logistic regression, which is used when there are more than two discrete possibilities for the dependent variable. The multinomial logit model generally captures how households' socio-economic and demographic variables affect the probability that a household in the sample exhibit any of the identified possible levels of food security states in reference to completely food secure households. As noted by Bhat (2003), the use of multinomial logit model is often an important econometric strategy when the choices are unordered. In this case, the test of independence of irrelevant alternatives (IIA) assumption of this model is required. IIA in the context of the present study implies that the odds of choosing completely food secure households as reference households is not affected by the existence of other levels of food security $(m=1,2,3)$. In other words, even if households in other levels of food security are taken as a reference point, the outcomes or estimated parameters are expected to be the same. Subsequently, we test the assumption of IIA and the result confirms the suitability of multinomial logit model in the study. We discuss this in detail in "Determinants of households in different levels of food security". 
Thus, following Greene (2008), we define the multinomial logit model for the study for $\mathrm{M}$ discrete alternatives $(m=0,1,2,3)$ as: ${ }^{1}$

$$
\begin{aligned}
& P_{\text {im }}=P\left(\mathrm{FS}_{\text {states }} \mid x_{i}\right) \forall m=0,1, \ldots \ldots . . m \\
& P_{\text {im }}=\frac{\exp \left(\beta_{i} x_{m}\right)}{1+\sum_{k=1}^{k=3} \exp \left(\beta_{i} x_{m}\right)}, \text { if } m=1,2,3 \\
& P_{\text {im }}=\frac{1}{1+\sum_{k=1}^{k=3} \exp \left(\beta_{i} x_{m}\right)}, \text { if } m=0
\end{aligned}
$$

where $P_{i m}$ is the probability indicator for $i$ th household in the M's FS_states; $x$ is the vector of households' socio-economic and demographic variables (see: Table 1 for the list of the variables); $\beta$ is the vector of parameters to be estimated; $m=1$ for food insecure households based on DDS indicator only; $m=2$ for food insecure households based on FOOD ${ }_{\text {exp }}$ indicator only; $m=3$ for food insecure households based on both indicators.

\section{Determinants of household demand for dietary diversity}

Household demand for dietary diversity (DD) has always been modeled in the literature with either DDS, which represents count data, or DDI that represents indices. For example, Hoddinot and Yohannes (2002) and more recently, Woldehanna and Behrman (2013) and Ecker et al. (2013) employed DDS, while Thiele and Weiss (2003), Drescher et al. (2007), and Gaiha et al. (2012) utilized DDI in their respective studies. ${ }^{2}$ In order to examine the household social-economic and demographic determinants of DD, we implicitly specify the relationship between DD, household income $Y_{i}$ and household demographic variables $x^{\prime}$ as follows:

$$
\mathrm{DD}_{i}=\psi_{0}+\phi Y_{i}+\beta x^{\prime}+\eta_{i}
$$

where, DD is the vector of DDS and DDI defined as $D D_{i}=\left[D D S_{i}, D D I_{i}\right]^{\prime} ; Y_{i}$ and $x$ are variables hypothesized to explain DD; $\psi_{0}, \phi$ and $\beta$ are parameters to be estimated; and $\eta_{i}$ is the random error of the fractional response regression.

Similar to the work of Thiele and Weiss (2003) and Drescher et al. (2007), we construct the DDI from household food expenditure, which has been aggregated across food groups using Berry index defined below: ${ }^{3}$

$$
\mathrm{DDI}_{i}=1-\sum_{j=1}^{J} w_{j i}^{2} \forall j=1,2, \ldots \ldots \ldots . . .
$$

where DDI is as defined earlier and ranges between 0 and 1 , with a value towards $1 \mathrm{im}$ plying higher dietary diversity and $w_{j i}$ is the expenditure share of $j$ th (in the study, $j=6$ ) food group relative to the total expenditure on food by the $i$ th households.

Since the data generating process (DGP) for both DDS and DDI are count and index data respectively, the estimation of Eq. 21 by traditional ordinary least square (OLS) will lead to inefficient results. As a result, we employ appropriate econometric technique applicable to each of the dependent variable. We further discuss about the econometric approaches in the next subsection. 
Table 1 Summary statistics of the variables and food security status

\begin{tabular}{|c|c|c|c|}
\hline Description & Variable & Mean & Std. dev. \\
\hline Dietary diversity score & DDS & 4.5739 & 1.2547 \\
\hline Real monthly per capita food expenditure & $F O O D_{\exp }$ & $16,084.9$ & $12,946.2$ \\
\hline \multicolumn{4}{|l|}{ Food insecurity (FI) indicator 1: identified food security states } \\
\hline Completely food insecure households from both indicators & FS_states $=3$ & 0.1574 & \\
\hline $\begin{array}{l}\text { Transitory food insecure based on FOOD } \exp \& \text { food secure } \\
\text { based on DDS }\end{array}$ & FS_states $=2$ & 0.2394 & \\
\hline $\begin{array}{l}\text { Transitory food insecure based on DDS \& food secure based } \\
\text { on FOOD } \exp \end{array}$ & FS_states $=1$ & 0.1788 & \\
\hline Completely food secure households from both indicators & FS_states $=0$ & 0.4244 & \\
\hline \multicolumn{4}{|l|}{ Food insecurity (FI) indicator 2: Dietary Diversity Index } \\
\hline Average Dietary Diversity Index & $D D /$ & 0.5849 & 0.1892 \\
\hline $\begin{array}{l}\text { Real per capita total expenditure in Naira—a proxy for } \mathrm{HH} \\
\text { income }\end{array}$ & HH_INCOME & $28,678.08$ & $32,724.82$ \\
\hline Household size & HHSIZE & 4.8479 & 2.9067 \\
\hline Average year of education of the Household head (in years) & EDUCATION & 7.3680 & 7.3580 \\
\hline Household head that are male $(1 / 0)$ & D_GENDER & 0.8562 & 0.3509 \\
\hline Household head with farming as major occupation (1/0) & D_OCCUPATION & 0.6257 & 0.4839 \\
\hline Households that only home-produced food consumed (1/0) & D_OWNPRODUCEONLY & 0.0139 & 0.1172 \\
\hline Household that only purchase food consumed (1/0) & D_PURCHASEONLY & 0.3083 & 0.4618 \\
\hline Households with member within <25 years $(1 / 0)$ & D_AGE $<20$ & 0.0221 & 0.1470 \\
\hline Households with member within 25-29 years (1/0) & D_AGE25-29 & 0.0659 & 0.2481 \\
\hline Households with member within 30-34 years (1/0) & D_AGE30-34 & 0.1042 & 0.3056 \\
\hline Households with member within 35-39 years (1/0) & D_AGE35-39 & 0.1226 & 0.3279 \\
\hline Households with member within 40-44 years (1/0) & D_AGR40-44 & 0.1321 & 0.3386 \\
\hline Households located in the rural areas $(1 / 0)$ & D_RURAL & 0.7613 & 0.4263 \\
\hline Households located in the south-south SS region (1/0) & D_SOUTH-SOUTH & 0.1512 & 0.3583 \\
\hline Households located in the south-east SE region (1/0) & D_SOUTH-EAST & 0.1421 & 0.3492 \\
\hline Households located in the south-west SW region (1/0) & D_SOUTH-West & 0.1697 & 0.3754 \\
\hline Households located in the north-central NC region (1/0) & D_NORTH-CENTRAL & 0.1768 & 0.3815 \\
\hline Households located in the north-west NW region (1/0) & D_NORTH-WEST & 0.2014 & 0.4010 \\
\hline
\end{tabular}

${ }^{a}$ Note: Expenditure is expressed in Nigerian currency (naira) and 1US\$ = 133 naira as at 2003/2004; Variables with D stands for dummies

Zero-truncated Poisson regression model for DDS As earlier stated, the DDS is a "count" data. Thus, similar to Rashid et al. (2011) we made use of zero-truncated Poisson regression model to estimate Eq. 21 when DDS is used as the dependent variable. In this regard, we assume DDS is random and, in a given time interval, has a Poisson distribution with probability density defined as:

$$
\operatorname{pr}\left(y_{i}=D D S_{i}\right) \frac{=e^{-\lambda_{i}} \lambda^{D D S_{i}}}{D D S_{i} !}, \operatorname{DDS}_{i}=1,2, \ldots \ldots 6
$$

where DDS is the realized value of a random variable with mean and variance $y_{i}$ and $\lambda_{i}$ respectively. $y_{i}$ is assumed to be strictly positive $\left(y_{i}>0\right)$. According to Cameron and Trivedi (1998), this is a case of truncation from below that is taken into account when specifying a zero-truncated Poisson model. 
To incorporate the set of explanatory variables $x$ and $Y$ stated in Eq. 21 into Eq. 23, and to ensure a non-negative mean $y_{i}$, the parameter $\lambda_{i}$ is specified as:

$$
E\left\{y_{i} \mid Y_{i}, x_{i k}\right\}=\lambda_{i}=\exp \left(\phi Y_{i}, x^{\prime} \beta\right)=\exp \left(\psi_{0}+\phi \mathrm{Y}_{i}+\beta_{1} x_{1}+\ldots . . \beta_{k} x_{k}\right)
$$

The implicit assumption in the Poisson model is that the variance $\lambda_{i}$ is equal to its mean $y_{i}$ or the data are equally dispersed. Any violation of this assumption has consequences similar to the failure of the assumption of homoscedasticity in the linear regression model (Cameron and Trivedi 1998).

Fractional regression model for DDI $_{i}$ Since DDI is bounded between 0 and 1 as earlier mentioned, Papke and Wooldridge (1996) argue that such indices is a fractional/ proportional data, and it can be better handled by fractional regression model proposed by the same authors. McDonald (2008) shows that the use of OLS, Tobit, and transformed logistic-normal model for fractional dependent variable data would yield inefficient results because the distribution of error terms is likely to be heteroskedastic. ${ }^{4}$ This is because, as the conditional variance of the error term approach zero, the conditional mean approaches either of the boundary points of the fractional data.

Thus, Papke and Wooldridge (1996) proposed Quasi-Maximum Likelihood Estimation (QMLE) to estimate the fractional regression model. ${ }^{5}$ This model has been widely adopted in similar studies (McDonald 2008; Sauer et al. 2011; Ogundari 2014).

The Bernoulli Log-likelihood function for estimating Eq. 21 when DDI is taken as the dependent variable is specified as:

$$
L_{i}(\beta) \equiv \mathrm{DDI}_{i} \ln \left(G\left(x^{\prime}\right)\right)+\left(1-\mathrm{DDI}_{i}\right) \ln \left(1-G\left(x^{\prime}\right)\right)
$$

where $0 \leq \mathrm{DDI}_{i} \leq 1$ denotes the dependent variable while $x^{\prime}$ refers to the explanatory variables of observation $i$.

Accordingly, Eq. 25 is well defined for $0<G\left(y, x_{i}\right)<1$. The QMLE of $\beta$ is obtained by simply maximizing Eq. 25. Papke and Wooldridge (1996) show that Bernoulli QMLE $\beta$ is consistent and $\sqrt{N}$-asymptotically normal regardless of the distribution of $D D I_{i}$ conditional on $y$ and $x^{\prime}$. In addition to its consistency and asymptotic normality, this approach does not require any data adjustments for the extreme values and the conditional expectation of $\mathrm{DDI}_{i}$, given the explanatory variables are estimated directly. Asymptotically efficient, unbiased, and consistent estimates are obtained from the QMLE by simply transforming $G\left(y, x^{\prime}\right)$ to produce models similar to either logit or probit in the binary choice situation (McDonald 2008). Papke and Wooldridge (1996) used a logistic function for $G\left(y, x^{\prime}\right)$ in the framework of generalized linear models (GLM) [that is, $\left.G\left(y, x^{\prime}\right)=\frac{\exp \left(y, x^{\prime}\right)}{1+\exp \left(y, x^{\prime}\right)}\right]$ which was extensively discussed in their paper. QMLE is estimated by weighted non-linear square allowing for heteroskedasticity and testing procedures, which are asymptotically efficient within a class of estimators (Oberhofer and Pfaffermayr 2009). ${ }^{6}$

In the meantime, QMLE fractional regression employed for the empirical analysis of Eq. 21 when DDI is considered as the dependent variable is specified as: 


$$
\mathrm{E}\left(\mathrm{DDI}_{i} \mid Y_{i}, x_{k}\right)=G\left(\psi_{0}+\phi Y_{i}+\sum_{k=1}^{K} \beta_{k} x_{k i}+\eta_{i}\right)
$$

where $\mathrm{DDI}_{i}$ is as earlier defined, $x_{k}$ and $Y_{i}$ represent the hypothesized variables to explain $\operatorname{DDI}_{i}, \psi_{0}$ and $\phi$ and $\beta$ are parameters to be estimated, $G($.$) is the logistic function$ while $\eta$ represents the error term.

\section{The data description}

The study employs data from Nigeria Living Standard Survey (NLSS) conducted from September 2003 to August 2004. The sampling design of the NLSS involves a twostage stratified random sampling technique. The first stage was a cluster of housing units called Enumeration Area (EA), while the second stage was the random selection of the housing units. There were seven interviewer visits to each selected household at a minimum of 4-day intervals in a cycle of 30 days. Questionnaires were used to obtain information on non-food expenditure, daily food consumption and expenditure, home-produced food, and purchased food items by the households. The NLSS contains information on 19,158 households. We made use of 18,870 households because 288 households had incomplete relevant information.

The information contained in the NLSS includes a detailed value of own-produced food and expenditure on the type of food purchased by the households. For each household, expenditure profile on the following six food groups were included: (1) staples \{which include yam, cocoyam, cassava, rice, maize, and millet\}, (2) meat and fish, (3) dairy products, (4) fruits and vegetables, (5) fats \& oils, (6) sweeteners. Also in the dataset are detailed information on the non-food expenditure, which includes expenditure on education, healthcare, housing (house rent, cost of maintaining the house and the furniture), clothing (clothes, shoes), utilities, house appliance, transportation (transport fares, petrol purchased, maintenance of cars, bicycles), and communication. Others information obtained include household's demographic variables such as: gender, years of education, major occupation of household head, age, and household size. The definition and summary statistics of the variables used in the analysis are presented in Table 1.

\section{Results and discussion}

\section{Proportion of households in different levels of food security in Nigeria}

As mentioned in "Household level food security states", the study combines two food security indicators defined as food expenditure $\left(\mathrm{FOOD}_{\exp }\right)$ and dietary diversity score (DDS) to categorize households in the sample into different FS_states. For FOOD exp, the threshold for the classification of households as food secure or insecure is taken as 10,723.3 Naira/month, which represent two thirds of mean per capita food expenditure. We consider also the average DDS of households in the upper quintile as the threshold to classify households into food secure/insecure, and this is equivalent to $4.8 \mathrm{food}$

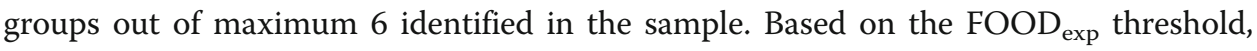
results suggest that about $66 \%$ of the households are regarded as food secure. On the other hand, results show that $60 \%$ of the households are food secure according to the DDS threshold adopted. Our finding is consistent with previous findings from Nigeria and other SSA countries. In Nigeria, Babatunde et al. (2007) found that about 38\% of 
the households are food insecure while the results of Omonona and Adetokunbo (2007) show that about $49 \%$ of households are food insecure. In Ethiopia, Feleke et al. (2005) reported about $40 \%$ incidence of food insecurity.

When the two indicators were combined to categorize households in the sample into different levels of food security, the results show that about $42 \%$ of the households in

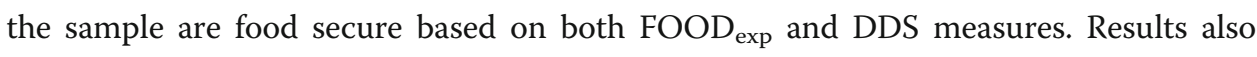
suggest that $18 \%$ of the sample could be classified as transitory food insecure households when $\mathrm{FOOD}_{\exp }$ was used as an indicator. About $24 \%$ of the households are categorized as transitory food insecure households based on DDS. About 16\% of the households are classified as completely food insecure when both measures were jointly used as an indicator (see Table 2 for details).

These results show that by combining two indicators to stratify households in the sample into different levels of food security, a comprehensive overview of the nature of food security issues is revealed. Thus, relevant specific policies can be targeted towards vulnerable households in each state or level of food security. For instance, households who are transitory food secure based on DDS indicator can be targeted with policies that could boost household economic access to food. Another importance of these results is that it prevents over characterization of households into food secure categories. Studies that are based on single indicator would have characterized the transitory food secured households as food secure household when in reality, they are not. These might explain why the issue of food security continues to linger despite various national and international interventions because an outcome of single-indicator studies does not tell the complete story of food insecurity. For instance, our estimates show that about 66 and $60 \%$ of the households in the sample were food secure based on a single indicator such as FOOD $\exp$ and DDS, respectively. However, by harmonizing the two indicators our results are able to show that about $42 \%$ of the households were actually food secure. The implication of this is that about 24 and $18 \%$ of the households regarded as transitory food insecure based on DDS and FOOD exp respectively were wrongly classified as food secure households from a single indicator stand point (see Table 2). Therefore, harmonizing food security indicators is not only consistent with the broad concept of food security but is also necessary to tell the full story of food insecurity. Such approach could help identify households with different nature of food (in) security problems that require different types of policy interventions most especially in developing economies like Nigeria. Likewise, we believe this

Table 2 Categorizing households into different food security states

\begin{tabular}{|c|c|c|c|c|}
\hline \multirow{2}{*}{$\begin{array}{l}\text { Categorization of households after } \\
\text { combining food security indicators }\end{array}$} & \multicolumn{2}{|c|}{ Food security indicators } & \multirow{2}{*}{$\begin{array}{l}\text { Proportion } \\
\text { of household } \\
\text { under different } \\
\text { states (\%) }\end{array}$} & \multirow{2}{*}{$\begin{array}{l}\text { Discrete } \\
\text { variable } \\
\text { representing } \\
\text { food security } \\
\text { states [FS_states] }\end{array}$} \\
\hline & DDS & $\mathrm{FOOD}_{\exp }$ & & \\
\hline Completely food insecure households & Never satisfy & Never satisfy & 15.74 & FS_states $=3$ \\
\hline Transitory food insecure households & Never satisfy & Satisfy & 23.84 & FS_states $=2$ \\
\hline Transitory food insecure households & Satisfy & Never satisfy & 17.88 & FS_states $=1$ \\
\hline Completely food secure households & Satisfy & Satisfy & 42.44 & FS_states $=0$ \\
\hline
\end{tabular}

Note: A transitory food insecure e households are those who are partially food secure based on one indicator; satisfy implies that food security indicators greater than threshold, never satisfy implies that food security indicators less than threshold 
approach could also help channel limited resources specifically to households that most needed urgent attention in the country.

\section{Determinants of households in different levels of food security}

Before we go into the socio-economic and demographic determinants of household in the identified levels of food security, it is important to discuss whether the data used in the study fulfills the independence of irrelevant alternative (IIA) assumption for the multinomial logit model. Similar to the work of Hausman and McFadden (1984), the present study uses Hausman-McFadden test under the null hypothesis of no systematic change in the coefficients when one of the outcomes from the model is excluded. We obtain a $p$ value of 0.8553 which suggest that there is no evidence that the IIA assumption has been violated.

It is also important to mention that we are aware of possible endogeneity of total expenditure used as a proxy for household income in the study. We thus correct for the endogeneity problem using the income of household head as a relevant instrument for the total expenditure within the framework of Durbin-Wu-Hausman test. ${ }^{7}$ We regress total expenditure on the income of the household head and other explanatory variables outlined in Table 1 as first stage regression. ${ }^{8}$ Thereafter, we conduct a test to confirm the relevance of the instrument and the result was found to be significant with a $p$ value of 0.000 and an F-statistics of 23.1. Thus, the predicted fitted value of the instrumented-total expenditure is then used in the final analysis reported in Tables 3 and 4 as HHINCOME. As noted by Rashid et al. (2011), this type of approach is becoming increasingly popular in the absence of detailed information on household income.

The results of the multinomial model showing the effects of household's socioeconomic and demographic characteristics on the probability of households being food insecure, are presented in Table 3. The results show that the probability of households in any of the identified food insecure states decreases significantly and consistently with household size and income, if a household buys all its food, if a household has more members aged below 44 years relative to those with members aged above 44 years, and if a household is located in the south-south, south-east, north- central, south-west, and north-west regions relative to households in the north-east region. The probability under consideration, however, increases consistently for households that consume only home-produced food, and for households with higher education. This may be because of reduced returns to education beyond the basic level and this is evident from the widespread unemployment in Nigeria. These results underscore policy relevance of household financial capabilities or resources, as this can change the lots of food insecure households, enabling them to gain access to adequate food because they are able to participate in food markets of their choice. The finding also draws our attention to the fact that home-produced foods are not enough to guarantee household food security. This supports the findings of Rose and Chariton (2002) that households that depend on own production had a higher probability of being food insecure.

Other results show that farming as occupation of the household head increases the probability of a household being food insecure based on DDS only, but decreases based on FOOD ${ }_{\text {exp }}$ only. Also, farming occupation has no significant effect on the probability 
Table 3 Socio-economic and demographic determinants of households being different foodpoverty states

\begin{tabular}{|c|c|c|c|c|c|c|}
\hline \multirow[t]{2}{*}{ Explanatory variables } & \multicolumn{2}{|c|}{$\begin{array}{l}\text { Probability of food } \\
\text { insecure HH based on } \\
\text { DDS indicator only }\end{array}$} & \multicolumn{2}{|c|}{$\begin{array}{l}\text { Probability of food insecure } \\
\mathrm{HH} \text { based on FOOD } \\
\text { indicator only }\end{array}$} & \multicolumn{2}{|c|}{$\begin{array}{l}\text { Probability of food } \\
\text { insecure HH from } \\
\text { both indicators }\end{array}$} \\
\hline & Coefficients & Std. error & Coefficients & Std. error & Coefficients & Std. error \\
\hline LOG_HHINCOME ${ }^{a}$ & $-0.5658^{* * *}$ & 0.1331 & $-4.4065^{* * *}$ & 0.1115 & $-3.4135^{* * *}$ & 0.1213 \\
\hline LOG_HHSIZE & $0.4718^{* * *}$ & 0.0759 & $-0.7135^{* * *}$ & 0.0648 & $-0.4732^{* * *}$ & 0.0722 \\
\hline LOG_EDUCATION & $0.0263^{* *}$ & 0.0103 & $0.1417^{* * *}$ & 0.0200 & $0.0824^{* * *}$ & 0.0112 \\
\hline D_OCCUPATION (farming) & $0.2788^{* * *}$ & 0.0688 & $-0.6453^{* * *}$ & 0.0653 & 0.7501 & 0.0737 \\
\hline D_GENDER (male) & -0.1029 & 0.0649 & -0.0186 & 0.0724 & 0.0273 & 0.0798 \\
\hline D_HOMEPRODUCEDONLY & $1.5369^{* * *}$ & 0.5955 & $1.6638^{* * *}$ & 0.5321 & $1.6620^{* * *}$ & 0.5451 \\
\hline D_PURCHASEONLY & $-0.2780^{* * *}$ & 0.0695 & $-0.0930^{* *}$ & 0.0447 & $-0.4131^{* * *}$ & 0.0698 \\
\hline D_AGE $<25$ & $-0.2322^{*}$ & 0.1340 & -0.0628 & 0.1789 & 0.1205 & 0.1764 \\
\hline D_AGE25-29 & $-0.1940^{* *}$ & 0.0849 & -0.1075 & 0.1014 & $-0.1834^{*}$ & 0.1093 \\
\hline D_AGE30-34 & $-0.2683^{* * *}$ & 0.0734 & $-0.3341^{* * *}$ & 0.0771 & $-0.2709^{* * *}$ & 0.0818 \\
\hline D_AGE35-39 & $-0.3199^{* * *}$ & 0.0703 & $-0.2984^{* * *}$ & 0.0684 & $-0.3526^{* * *}$ & 0.0745 \\
\hline D_AGE40-44 & $-0.1847^{* * *}$ & 0.0689 & -0.0926 & 0.0640 & $-0.1503^{* *}$ & 0.0699 \\
\hline D_RURAL & $0.2324 * * *$ & 0.0735 & $-0.5887^{*}$ & 0.0700 & 0.0204 & 0.0804 \\
\hline D_SOUTH-SOUTH & $-0.7338^{* * *}$ & 0.0778 & $-0.1636^{* *}$ & 0.0838 & $-0.5022^{* * *}$ & 0.0897 \\
\hline D_SOUTH-EAST & $-1.0018^{* * *}$ & 0.0824 & $-0.3004^{* * *}$ & 0.0962 & $-0.7490^{* * *}$ & 0.1024 \\
\hline D_SOUTH-WEST & $-0.3327^{* * *}$ & 0.0775 & $-0.8411^{* * *}$ & 0.0871 & $-1.0147^{* * *}$ & 0.0929 \\
\hline D_NORTH-CENTRAL & $-0.7022^{* * *}$ & 0.0833 & $-0.2828^{* * *}$ & 0.0856 & $-0.6943^{* * *}$ & 0.0930 \\
\hline D_NORTH-WEST & $-0.4174^{* * *}$ & 0.0796 & $-1.0142^{* * *}$ & 0.0858 & $-0.8237^{* * *}$ & 0.0886 \\
\hline Constant & $5.8412^{* * *}$ & 1.4659 & $45.3757^{* * *}$ & 1.2039 & $34.0435^{* * *}$ & 1.3198 \\
\hline
\end{tabular}

***,*** Implies that the estimated parameters are significantly different from zero at 1, 5, and $10 \%$ significance level, respectively. Figures in parentheses are standard error

${ }^{a}$ We use income of household as instrument on total expenditure taken as a proxy for household income in the study

of being food insecure based on both indicators. Results also suggest that the gender of the household head does not exhibit any significant impact on the level of household food security in the study. Among rural households, the probability of being food insecure increases based on DDS, but decreases based on FOOD exp. The probability of being a food insecure household based on both indicators increase among rural households relative to their urban counterpart.

In general, these findings show that household socio-economic and demographic characteristics differ in their effects on the probability of households being in the identified states of food security. Furthermore, the results also suggest that categorizing households into different states or levels of food security by combining two-food security indicators reflect nuances that might have been impossible to uncover with just an indicator.

\section{Determinants of household demand for dietary diversity ${ }^{9}$}

Table 4 presents the determinants of household demand for dietary diversity (DD) when DDI and DDS are used as indicators of food security in the study. The Table shows that both the DDI and DDS provide similar significant results. On this basis, as income increases, household diet becomes more diverse. This is consistent with the 
Table 4 Determinants of household demand for dietary diversity

\begin{tabular}{|c|c|c|c|c|}
\hline \multirow[t]{2}{*}{ Variables } & \multicolumn{2}{|c|}{ DDI estimates ${ }^{a}$} & \multicolumn{2}{|c|}{ DDS estimates ${ }^{a}$} \\
\hline & Coefficients & Std. error & Coefficients & Std. error \\
\hline LOG_HHINCOME ${ }^{b}$ & $0.3222^{* * *}$ & 0.0106 & $0.1759^{* * *}$ & 0.0039 \\
\hline LOG_HHSIZE & $0.1739 * * *$ & 0.0108 & $0.1200^{* * *}$ & 0.0038 \\
\hline LOG_EDUCATION & $-0.0152^{* * *}$ & 0.0043 & $-0.0107^{* * *}$ & 0.0015 \\
\hline D_GENDER & -0.0162 & 0.0157 & 0.0043 & 0.0056 \\
\hline D_OCCUPATION & $0.2821^{* * *}$ & 0.0168 & $0.0956^{* * *}$ & 0.0062 \\
\hline D_HOMEPRODUCEDONLY & $-2.0441^{* * *}$ & 0.1416 & $-1.8111^{* * *}$ & 0.1236 \\
\hline D_PURCHASEONLY & $0.5385^{* * *}$ & 0.0187 & $0.1374^{* * *}$ & 0.0068 \\
\hline D_AGE $<25$ YEARS & $0.1468^{* * *}$ & 0.0335 & $0.0475^{* * *}$ & 0.0121 \\
\hline D_AGE25-29 YEARS & $0.1249^{* * *}$ & 0.0208 & $0.0496^{* * *}$ & 0.0076 \\
\hline D_AGE30-34 YEARS & $0.0987^{* * *}$ & 0.0176 & $0.0504^{* * *}$ & 0.0063 \\
\hline D_AGE35-39 YEARS & $0.0985^{* * *}$ & 0.0161 & $0.0509^{* * *}$ & 0.0057 \\
\hline D_AGE40-44 YEARS & $0.0389^{* * *}$ & 0.0156 & $0.0238^{* * *}$ & 0.0056 \\
\hline D_RURAL & $0.2239^{* * *}$ & 0.0162 & $0.0658^{* * *}$ & 0.0060 \\
\hline D_SOUTH-SOUTH & $0.1775^{* * *}$ & 0.0175 & $0.1133^{* * *}$ & 0.0065 \\
\hline D_SOUTH-EAST & $0.1900^{* * *}$ & 0.0179 & $0.1127^{* * *}$ & 0.0064 \\
\hline D_SOUTH-WEST & $0.3345^{* * *}$ & 0.0188 & $0.1076^{* * *}$ & 0.0068 \\
\hline D_NORTH-CENTRAL & $-0.3412^{* * *}$ & 0.0234 & $-0.1003^{* * *}$ & 0.0094 \\
\hline D_NORTH-WEST & $0.1261^{* * *}$ & 0.0186 & $0.0794^{* * *}$ & 0.0069 \\
\hline CONSTANT & $-3.6708^{* * *}$ & 0.1248 & $-0.6249^{* * *}$ & 0.0462 \\
\hline \multicolumn{5}{|l|}{ Model Diagnostics (DDI/DDS) } \\
\hline Log Pseudo Likelihood / Prob. > F & \multicolumn{2}{|l|}{-8582.43} & \multicolumn{2}{|l|}{$-33,866.013$} \\
\hline Sample size & \multicolumn{2}{|l|}{18,870} & \multicolumn{2}{|l|}{18,870} \\
\hline
\end{tabular}

***,***Implies that the estimated parameters are significantly different from zero at 1,5, and $10 \%$ significance level, respectively. Figures in parentheses are standard error ${ }^{a}$ Both DDI and DDS were estimated with robust option

${ }^{b}$ We use income of household as instrument on total expenditure taken as a proxy for household income in the study

finding of Langat et al. (2010), and Woldehanna and Behrman (2013) for households in Kenya, and Ethiopia respectively. Our finding, according to Thiele and Weiss (2003), is consistent with the hypothesis that consumption evolves along hierarchical order as income increases.

Other results also show that household dietary diversity increases significantly as household size increase. This is similar to the findings of Rashid et al. (2011), and Woldehanna and Behrman (2013) for households in Bangladesh and Ethiopia, respectively. This result might be arising from the additional sources of income that may be accruing to the household in a situation where most of the members of the household are involved in some income-generating activities.

The education of the household head, which can be taken as a proxy for consumer dietary knowledge and ability to process dietary information has a significant negative relationship with the demand for dietary diversity. This finding is in contrast with previous findings that found households whose head is educated to have higher demand for dietary diversity (Variyam et al. 1998; Rashid et al. 2011, and Woldehanna and Behrman 2013). Also, being a male-headed household has significant negative relationship with the demand for dietary diversity. This result is not surprising because maleheaded household dominated the sample used in the study as evident in Table 1. For 
instance, a typical male-headed household in traditional Africa society is not involved in decision on what to eat and type of food items to purchase in the household food budget.

The results further show that the demand for dietary diversity significantly increases among households headed by farmers in the study, in contrast to what was obtained by Thiele and Weiss (2003) in Germany, where being a farmer means having decreased food diversity. While dietary diversity significantly decreases among households that consume only home-produced food, households that rely only on purchased food have higher dietary diversity. This suggests that dietary diversity of the farmer may be limited by farm size, seasonal and agronomic constraints. Households consuming only purchased food, on the other hand, are not as constrained as the market contains foods sourced from different areas.

The results further show that households whose members are less than 40 years old have a higher demand for higher dietary diversity compared to households whose members are all above 40 years old. This is possible, because those under 40 years have to consume as many nutritional foods as possible to be in the possession of the physical and mental capacities needed to engage in the education and labour activities. Households in rural areas have a higher demand for dietary diversity, relative to households in urban areas. This contradicts Thiele and Weiss' (2003) argument that households in cities tend to have a higher demand for dietary diversity than people living in the rural environment, possibly because foods are less expensive in Nigerian rural areas relative to urban. Relative to households in the north-east region of Nigeria, households in the north-west, south-west, south-east, and south-south regions of the country exhibit higher and significant demand for dietary quality.

\section{Conclusions}

The absence of an all-encompassing indicator of food security limits the extent to which panoptic food security policies can be made from existing indicators. Harmonization of indicators of food security to capture its multidimensional concept in an effort to derive clearer policy conclusions from the empirical analysis has been suggested in the literature. This ensures proper identification of households into different regimes of food security, provides opportunities to target households with different types of policy intervention, help channel policy instruments specifically to households that are most vulnerable, and most importantly provides information on different groups of households with different types of food (in) security problem.

As a result, this study uses a novel idea to combine two popular indicators of food security namely food expenditure $\left(\mathrm{FOOD}_{\text {exp }}\right)$ and dietary diversity score (DDS) in the literature to categorize households in Nigeria into four possible states of food security, namely completely food insecure households as revealed by both indicators, transitory

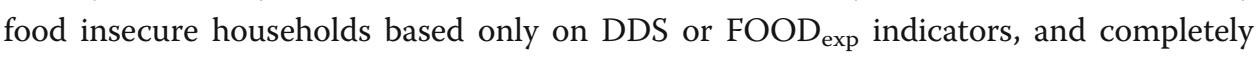
food secure households as revealed by both indicators. Subsequently, we use a multinomial logit model to examine how the socio-economic and demographic characteristics of households influence the probability that a household will be in one of the identified states of food security relative to food secure households. Also, using DDS and dietary diversity index (DDI) as additional sets of indicators of food security and 
zero-truncated Poisson and fractional regression models, we further investigate the determinants of dietary diversity in Nigeria.

Our estimates show that about 66 and $60 \%$ of the households in the sample were food

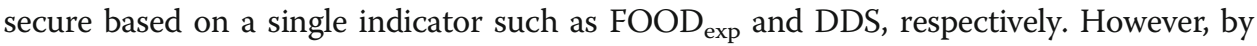
harmonizing the two indicators our results reveal that about $42 \%$ of the households were actually food secure. The implication of this is that about 24 and $18 \%$ of the households regarded as transitory food insecure based on DDS and FOOD exp $_{\text {respectively were }}$ wrongly classified as food secure households from a single indicator standpoint.

Also, the empirical results based on the multinomial logit model show that the probability of households being in any of the identified food insecure states relative to food secure households decreases significantly and consistently with income, household size, whether households consume only purchased food, and the geographical region of the household. This probability, however, increases if household consumes only home-produced food.

The results of the determinants of household demand for dietary diversity based on DDS and DDI show that dietary diversity increases with household income and household size, whether the household head is a farmer, whether households consume only purchased food, and whether households reside in the rural areas. We, however, found that educated household heads and those consuming only home-produced food consume less diverse diet. We also found that dietary diversity varies across Nigerian regions.

Therefore, harmonizing food security indicators is not only consistent with the broad concept of food security but is also necessary to tell the full story of food insecurity of households in Nigeria. Conversely, we believe this approach could help identify households with different nature of food (in) security problems that require different types of policy interventions most especially in developing economies like Nigeria. Likewise, we believe this approach could also help channel limited resources specifically to households that most needed urgent attention in the country. Also, understanding these factors that influence household's food security as well as household demand for dietary diversity is crucial in designing food policy programs that will effectively achieve the desired goals. For instance, our findings that household income decreases food insecurity and that home-produced food is not enough to guarantee food security raises the need for Nigeria to focus on market-based intervention policies. Such policies could facilitate households' access at all time to healthy foods of their choice. Such an intervention also gives households opportunity to benefit from greater varieties of food items offered by the market.

We suggest that future research should consider the role of food prices as determinants household food security in Nigeria. This is because we could not incorporate food prices in the analysis due to lack of data on food prices in the survey used for the analysis. In addition, it would be interesting to consider other popular food security indicators that capture effectively other dimensions of food security indicators such as crop yield (availability), calorie intake (accessibility), anthropometric measures (utilization), and coping strategy index (sustainability). Likewise, constructing healthy food diversity can also be explored in future research.

\section{Endnotes}

${ }^{1}$ The first FS_states denoted by 0 serves as the reference state and it represents households that are food secured. 
${ }^{2}$ As noted by Gao et al. (2013), although food diversity is related to diet quality, nevertheless, it may not be as good as measurement as the healthy eat index that is based on dietary guidelines.

${ }^{3}$ There are other frequently used indices such as entropy, Herfindahl, Simpson and among others. The present study employed Berry index because of its simplicity and also it has been used in the previous studies, which provide ease of comparison.

${ }^{4}$ The problem in using OLS on fractional dependent variable is that it is not asymptotically efficient estimator. It is an unbiased but inconsistent estimator.

${ }^{5}$ This is a departure from previous studies such as Thiele and Weiss (2003) and Drescher et al. (2007) that used transformed DDI as dependent variable before estimating with OLS; and from Gaiha et al. (2012) that employed OLS technique directly on the DDI.

${ }^{6} \mathrm{QMLE}$ accommodates naturally, non-constant variances and skewness (Oberhofer and Pfaffermayr 2009).

${ }^{7}$ The NLSS contains detail information on income of household head as information on income of other members of households are not readily provided.

${ }^{8}$ For brevity the result of the first stage regression is not presented. This can be requested from the author.

${ }^{9}$ This section focuses on determinants of household demand for dietary diversity based on the identified six food groups used in the study. As noted by Rashid et al. (2011), it is not clear whether diversity between and within the identified food groups is determined by similar factors, which is a serious limitation of this study. Nevertheless, we believe the results obtained are consistent with previous studies, which thus stress further the policy relevance of the findings.

\section{Acknowledgements}

The author would like to thank the reviewer and editor of this paper for their thoughtful comments and suggestions on the earlier draft of this paper. The author equally thanks Dr. Olufemi Bolarinwa for reading and discussing the earlier draft of the paper. The views in this paper are the author's own and do not necessarily represent those of the University of Delaware.

\section{Competing interests}

The author declares no competing interests.

\section{Publisher's Note}

Springer Nature remains neutral with regard to jurisdictional claims in published maps and institutional affiliations.

Received: 9 September 2015 Accepted: 14 March 2017

Published online: 19 April 2017

\section{References}

Babatunde RO, Omotesho OA, Osholotan OS (2007) Economic characteristics and food security status of farming household in Kwara state, North-central Nigeria. Pak J Nutr 6:49-58

Barret C (2010) Measuring food insecurity. Science 237:825-828

Becker GS (1981) Treatise on the family. Harvard University Press, Cambridge

Bhat CR (2003) Random utility-based discrete models for travel demand analysis. In: Goulias KG (ed) Transportation systems planning: methods and applications. CRC Press, Boca Raton, pp 10-30

Cameron AC \& Trivedi PK (1998) Regression Analysis of Counts Data. Cambridge University Press

Canagarajah S, Thomas S (2001) Poverty in wealthy economy: the case of Nigeria. J Afr Econ 10:143-173

Carletto C, Zezza A, Banergec R (2013) Towards better measurement of household food security: harmonizing indicator and the role of household surveys. Glob Food Sec 26:30-40

Drescher LS, Thiele S, Mensink GB (2007) A new index to measure healthy food diversity better reflects a healthy diet than traditional measures. J Nutr 137:647-651

Ecker O, Tan J-FT, Alpuerto V, Diao X (2013) Economic growth and agricultural diversification matters for food and nutrition security in Ghana. Ghana strategy support program, discussion note number 031. IFPRI, Washington DC

Faridi R \& Wadood SN (2010) An econometric assessment of household food security in Bangladesh. The Bangladesh Development Studies, XXXII: 97-111 
Feleke ST, Kilmer RL, Gladwin CH (2005) Determinants of food security in Southern Ethiopia at the household level. Agric Econ 33:351-363

Food and Agricultural organization (1996) Rome declaration on World Food Security., Worlds food submit. Food and Agricultural organization (FAO), Rome, Accessed Sept 2014

Food and Agricultural organization (2015) Regional overview of food insecurity: African food security prospects brighter than ever. FAO, Accra (Accessed July 2016)

Gaiha R, Kaieker H, Imai KS, Kulkarni VS, Thapa G (2012) Diet diversification and diet quality in India: an analysis. Discussion paper series RIEN DP 2012-30, Kobe University, Japan

Gao Z, Xiaohun Y, Lee J-Y (2013) Consumer demand for diet quality: evidence from the healthy eating index. Aust J Agric Resour Econ 57:301-319

Greene WH (2008) Econometric analysis, 6th edn. Prentice-Hall, New Jersey

Habicht J, Pelletier J (1990) The importance of context in choosing nutritional indicators. J Nutr 120S:1519-1524

Hausman J, McFadden D (1984) Specification test for the multinomial logit model. Econometica 52:1219-1240

Heady D \& Ecker O (2012) Improving the measurement of food security. IFPRI. Discussion Paper 01225.

Hendriks SL, Msaki MM (2009) The impact of smallholder commercialization of organic crops on food consumption patterns, dietary diversity and consumption elasticities. Agrekon 48:184-199

Hoddinot J (1999) Choosing outcome indicators of household food security. Technical Guides \#7. International Food Policy Research Institute (IFPRI), Washington D.C

Hoddinot J, Yohannes Y (2002) Dietary diversity as a food security indicator, FCND Discussion paper No. 136. International Food Policy Research Institute (IFPRI), Washington D.C

Langat BK, Salo TK, Nyangiweso PM, Ngeno VK, Korir MK, Kipsat MJ (2010) Household food security in commercialized subsistence economies: factors influencing dietary diversity of smallholder Tea farmers in Nandi South Kenya. Poster presented at the 3rd African Association of Agricultural Economist (AAAE) and 48th Agricultural Economist Association of South Africa (AEASA) conference, Cape Town

Lokosang LB, Ramroop S, Hendriks SL (2011) Establishing a robust technique for monitoring and early warning of food insecurity in post-conflict south-Sudan using ordinal logistic regression. Agrekon 50:101-130

Magana-Lemus D, Ishdorj A, Parr Rosson C, Lava-Alvarez J (2016) Determinants of household food insecurity in Mexico. Agric Food Econ 4(10):1-20

Magrini E \& Vigani M (2014) Technology adoption and multiple dimension of food security: the case of maize in Tanzania. LICOS Centre for Institutions and Economic Reforms. Discussion paper 352/2014.

McDonald J (2008) Using Least Squares and Tobit in Second Stage DEA Efficiency Analyses. Flinders Business School Research Paper Series 2008-3 ISSN 1441-3906. Flinders University Adelaide, USA

Obayelu AE (2013) Households' food security status and its determinants in the North-Central Nigeria. Food Econ 9 ; $241-256$

Oberhofer H \& Pfaffermayr M (2009) Fractional response models-A replication exercise of Papke and Wooldridge (1996). A working paper in Econometrics and Statistics, University of Innsbruck No.2009-02.

Ogundari K (2014) The paradigm of agricultural efficiency and its implication on food security in Africa: what does meta-analysis reveal? World Dev 64:690-702

Omonona BT, Adetokunbo AAG (2007) An analysis of food security situation among Nigerian urban households: evidence from Lagos state, Nigeria. J Cent Eur Agric 8:397-466

Pangaribowo EH, Gerber N, Torero M (2013) Food and nutrition security indicators: a review. Center for Development Research (ZEF), University of Bonn, Working paper No. 108, Bonn

Papke LS, Wooldridge JM (1996) Econometric methods for fractional response variables with an application to $401(\mathrm{~K})$ plan participation rates. J Appl Economet 11:619-632

Rashid DA, Smith L, Rahman T (2011) Determinants of dietary quality: evidence from Bangladesh. World Dev 39:22212231

Roberts MJ \& Schlenker W (2010) Why climate change impacts on agriculture could be economically substantial. In: Heal G (ed) Is Economic Growth Sustainable? IEA Conference Volume no. 148. Palgrave Macmillan

Rose D, Chariton KE (2002) Quantitative indicators from food expenditure survey can be used to target the food insecure in South Africa. J Nutr 132:3235-3242

Ruel MT (2012) Simple dietary diversity indicators: how well do they reflex micronutrient adequacy? Presentation at the FAO symposium

Sauer J, Davidora S, Latruffe L (2011) Determinants of smallholders' decisions to leave land fallow. The case of Kosovo. J Agric Econ 63:119-141

Singh I, Squire L, Strauss J (1986) Agricultural households models: extensions, application and policy. John Hopkins University Press, Baltimore

Smith LC, Subandoro A (2007) Measuring food security using household expenditure surveys. Food security in practice technical guide series. International Food Policy Research Institutes, Washington, D.C

Strauss J (1983) Socio-economic determinants of food consumption and production in rural Sierra Leone: application of an agricultural household model with several commodities. MSU International Development papers. Department of Agricultural Economics, Michigan State University, East Lansing

Thiele S, Weiss C (2003) Consumer demand for food diversity: evidence for Germany. Food Policy 28:99-115

USDA-ER (2012) International food security Assessment, 2012-22/GFA-23. U.S. Department of Agriculture, Economic. Economic Research Service publication, Washington DC

Variyam JN, Blaylock J, Smallwood D, Basiotis D (1998) USDA's Healthy Eating Index and nutrition information. Economic Research Service/USDA, Technical Bulletin, 166, Washington D.C

Woldehanna T, Behrman JR (2013) What determines Ethiopian children's dietary diversity. Paper presented at center for the study of African Economics (CSAE) held at St. Catherine's college Oxford 17-19 march 2013

Yu B, You L (2013) A typology of food security in developing countries. China Agric Econ Rev 5:118-153 